\title{
Partial replacement of conventional fine aggregate with crumb tyre rubber in structural concrete - effect of particle size on compressive strength and time dependent deformations
}

\author{
Kudzai Mushunje*, Mike Otieno and Yunus Ballim \\ University of the Witwatersrand, School of Environmental and Civil Engineering, Johannesburg, South Africa
}

\begin{abstract}
This paper presents results of a study into the effects of truck tyre crumb rubber particle size, as fine aggregate, on the compressive strength, shrinkage and creep behaviour of structural rubberised concrete. The study is motivated by a growing interest in the use of concrete with waste tyre rubber particles, rubberised concrete, for structural applications. Three tyre crumb rubber sizes $(2.36,1.18$ and $0.425 \mathrm{~mm}$ ) were used to replace $10 \%$ by volume of fine mineral aggregates to produce concrete with a target strength of $30 \mathrm{MPa}$. The concrete was cast water-cured for 28 days and tested for shrinkage and creep for 180 days. Half of the shrinkage and creep samples were sealed with a bitumen seal to prevent drying during testing. Results show a general a decrease in compressive strength with reduction in crumb rubber size. The strength decreases by $22 \%, 23 \%$ and $27 \%$ for the $2.36,1.18$ and $0.425 \mathrm{~mm}$ mix respectively. Preliminary results show a general increase in both shrinkage and creep deformations in both drying and sealed conditions. The observed increases were checked against the limits provided in design codes to assess the applicability of the material for structural purposes.
\end{abstract}

\section{Introduction}

Concrete is one of the most extensively used construction material in the world and the mineral aggregates used to make the concrete are a finite resource, which is fast dwindling. According to Alexander and Mindess [1] mineral aggregates are the most extensively used material after water and soil. With an estimated total annual global consumption of about 4.5 billion tons, their continued use at this rate is not sustainable given that they are a finite resource. There is, therefore, a need to find alternatives to virgin mineral aggregates. The recycling of building materials from demolished buildings like crushed brick and concrete has been suggested $[2,3]$. The attractiveness of most of these alternative aggregates is in their dual purpose. Firstly they reduce the amount of waste to be disposed of. Secondly, they reduce the amount of virgin aggregate used in concrete. In line with this initiative, the use of waste tyre rubber particles in concrete has been proposed, mainly as a possible waste tyre disposal method, but research has shown promising concrete property enhancements with the use of tyre rubber in concrete [4]. Some researchers report improved sound absorption and thermal insulation due to the inclusion of rubber in concrete [4-6]. A major shortcoming of using tyre rubber in concrete has been the marked reduction in its mechanical performance compared to conventional concrete. Researchers report notable reductions in the strength and elastic modulus of the rubberised concrete [6 - 12]. The reduction in the mechanical performance has been attributed to the significantly lower stiffness $(<5 \mathrm{MPa})$ of the rubber, the uneven distribution of the rubber aggregate due to its light weight and the poor bonding between the rubber aggregate and the cement paste [6 - 12]. Efforts have been made to limit the reduction in the mechanical performance of rubberised concrete by pretreating the rubber aggregate and making use of different binder types, like magnesium oxychloride cement and cements with supplementary cementitious materials (SCMs) (Fly ash and Silica fume) [13 - 16]. Rostami et al. [14] found that when crumb tyre rubber is pretreated with carbon tetrachloride, the rubberised strength improved by $57 \%$. Segre and Joekes [15] report an improvement of $17 \%$ in compressive strength when crumb rubber is pretreated with $0.1 \mathrm{M}$ Sodium Hydroxide $(\mathrm{NaOH})$. Changing the binder type has also resulted in rubberised concrete with sufficient strength $(>25 \mathrm{MPa})$ for structural applications. Pelliser et al. [17] made a $48 \mathrm{MPa}$ strength rubberised concrete, with $10 \%$ crumb rubber to fine mineral aggregate replacement by volume and a $15 \%$ silica fume-cement replacement at a water-to-binder ratio of 0.4 concrete mix. Other researchers $[6,18]$ also reported comparable results for a similar mix as well as an improvement in

\footnotetext{
* Corresponding author: Kudzai.Mushunje@students.wits.ac.za
} 
the permeability, chloride and sulphuric acid attack resistance of the rubberised concrete. Many other tyre rubber pre-treatment techniques and chemicals have been suggested with varied results but the trend has shown that it is possible to produce a structural rubberised concrete.

As research in the development of high strength rubberised concrete continues there has been an increasing call for the use of rubberised concrete for structural uses. This has been supported by research $[6$, 18] that has suggested that rubberised concrete has similar durability performance properties as conventional concrete and in some cases performing better. However, the full utilisation of rubberised concrete as a structural material in construction is only possible when its shrinkage and creep behaviour is sufficiently appreciated. This is because shrinkage and creep deformations are normally much larger than elastic deformations in concrete structures $[19,20]$. These deformations often result in excessive cracking and deflections or possible failure with an inherent loss in serviceability, durability and long-term safety of concrete structures $[19,20]$. A considerable amount of research has been done in order to understand the timedependent behaviour of conventional concrete because of the importance of this knowledge in ensuring safe, serviceable and durable structures. This study therefore aims to quantify the effects of crumb tyre rubber on shrinkage and creep deformation of structural concrete.

\section{Tyre rubber production and properties}

Tyre rubber aggregates are produced from waste tyres by either ambient or cryogenic grinding process. The ambient process is grinding or shredding of the tyres conducted at room temperature while the cryogenic process entails freezing the tyre under sub-zero temperatures and grinding thereafter [21]. The ambient process is the most commonly used process because of cost considerations but the cryogenic produces much cleaner tyre rubber particles [22]. The tyre rubber aggregate characteristics depend on the type of tyre used, the region where it was produced and the process used to make the rubber particles [21]. Waste tyre rubber material added to concrete is generally classified by size rather than use or composition. Though the cut-off sizes for each group differ, authors generally agree on three classes of waste tyre rubber particles $[13,23]$. The three main classes are shredded / chipped rubber $(13-73$ $\mathrm{mm})$, crumb rubber $(0.425-4.75 \mathrm{~mm})$ and ground rubber $(0.075-0.425 \mathrm{~mm})$ In the present investigation truck tyre crumb rubber particles produced by ambient grinding process are used. Truck tyre rubber consists of $65 \%$ natural rubber and $35 \%$ synthetic rubber [23]. Table 1 gives the general composition of different tyre types.

\section{Materials}

CEM I 52.5N plain Portland Cement (PC), conforming to SANS 50197-1\&2 [25, 26] was used to make the concrete. Crushed andesite with a relative density of 2.94 was obtained from Afrisam, Eikenhof quarry and was used as both fine and coarse mineral aggregate in the concrete. The maximum coarse aggregate size was 22 $\mathrm{mm}$ for concrete used for all tests samples. Truck tyre crumb rubber particles produced in an ambient grinding process by a local South African waste tyre recycler were used. Three crumb rubber sizes $(2.36 \mathrm{~mm}, 1.18 \mathrm{~mm}$ and $0.425 \mathrm{~mm}$ ) were utilised to make 4 concrete mixes including the control which had no tyre rubber aggregate. Fine aggregate was replaced by volume at $10 \%$ replacement level for all crumb rubber sizes to obtain concrete with a mean compressive strength of 30 $\mathrm{MPa}$. All the concrete mixes were cast with the same w/c ratio of 0.55 , without admixtures. The mix proportions of the concretes made are shown in Table 2 below.

Table 1. Material Composition of Tyres [24]

\begin{tabular}{|l|c|c|c|}
\hline \multirow{2}{*}{ Ingredient } & \multicolumn{3}{|c|}{ Percentage composition } \\
\cline { 2 - 4 } & Passenger & Truck & Off the Road \\
\hline Rubber & 47 & 45 & 47 \\
\hline Carbon black & 21.5 & 22 & 22 \\
\hline Metal & 16.5 & 25 & 12 \\
\hline Textile & 5.5 & - & 10 \\
\hline Zinc Oxide & 1 & 2 & 2 \\
\hline Sulphur & 1 & 1 & 1 \\
\hline Additives & 7.5 & 5 & 6 \\
\hline
\end{tabular}

Table 2. Mix Proportions $\left(\mathrm{kg} / \mathrm{m}^{3}\right)$

\begin{tabular}{|l|l|l|l|l|l|}
\hline Description & OPC & Water & $\begin{array}{l}\text { Coarse } \\
\text { Agg. }\end{array}$ & $\begin{array}{l}\text { Fine } \\
\text { Agg. }\end{array}$ & Crumb \\
\hline Control (CM) & 350 & 210 & 1050 & 790 & 0 \\
\hline $\begin{array}{l}2.36 \mathrm{~mm} \\
\text { crumb (M8) }\end{array}$ & 350 & 210 & 1050 & 672 & 53 \\
\hline $\begin{array}{l}1.18 \mathrm{~mm} \\
\text { crumb (M16) }\end{array}$ & 350 & 210 & 1050 & 672 & 53 \\
\hline $\begin{array}{l}0.425 \mathrm{~mm} \\
\text { crumb (M40) }\end{array}$ & 350 & 210 & 1050 & 711 & 34 \\
\hline
\end{tabular}

\section{Methodology}

\subsection{Tyre rubber characterisation}

A pycnometer was used to determine the specific gravity of the tyre rubber aggregate. The surface texture and shape of the crumb rubber were characterised using a scanning electron microscope (SEM). In order to view and capture the micrographs using the SEM, the rubber particles were coated with 2 layers of Gold Palladium.

\subsection{Compressive strength}

Compressive strength tests were used to characterise the concrete being tested. The compressive strength tests were carried out in accordance with South African National Standard (SANS 5863:2006) [27]. The concrete specimens were $100 \mathrm{~mm}$ cubes and were tested at 28 days of curing in water kept at a temperature of $23 \pm 2$ ${ }^{\circ} \mathrm{C}$. The workability of the concrete mix was evaluated by the slump test. 


\subsection{Creep}

Concrete prisms were cast using mould sizes of $710 \mathrm{x}$ $100 \times 100 \mathrm{~mm}$ for the shrinkage and creep tests. After approximately 20 days of curing, each concrete beam was cut into three $100 \mathrm{~mm} \times 200 \mathrm{~mm}$ prisms using a diamond saw and faced, on a high-speed facing machine to ensure that these ends were parallel to each other. Two stainless steel demec targets were attached to two opposite $100 \mathrm{~mm}$ × $200 \mathrm{~mm}$ faces of each prism using quick setting glue. After the glue had set, the prisms were returned to the water curing tank. For each mix, three prisms were used for creep test and another three for shrinkage test. The concrete prisms were cured in a water-curing tank for a total of 28 days before they were set up in the loading frames which are based on the ASTM C-512-15[28] creep frame, however the load is applied by a hydraulic flat jack. The arrangement is shown in Figure 1 below.

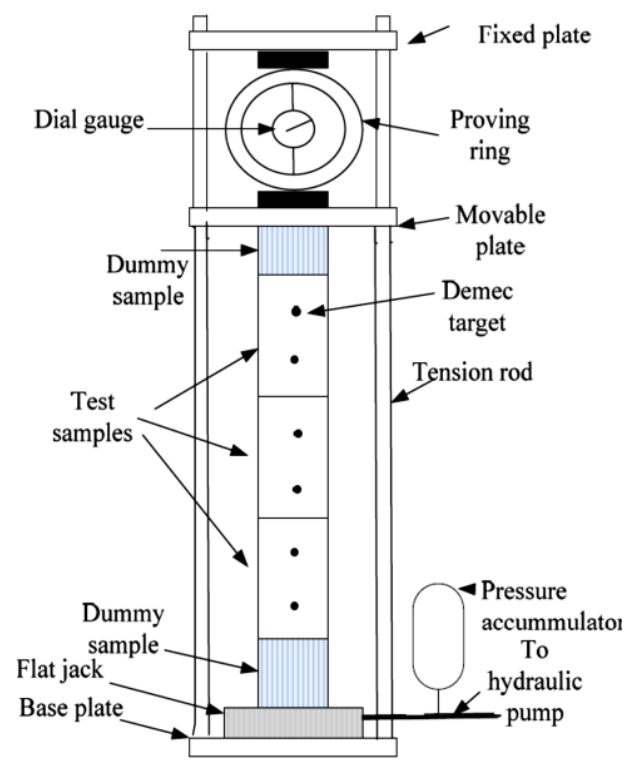

Fig 1. Creep loading arrangement

The creep frames are setup in a humidity- and temperature-controlled room. The temperature and relative humidity were maintained at $21 \pm 2{ }^{\circ} \mathrm{C}$ and $60 \pm$ $5 \%$ respectively. In the creep test samples were loaded at one-third of their compressive strength, determined from companion $100 \mathrm{~mm}$ cubes crushed at the same time the creep samples are removed from the curing bath. These stresses were maintained within $\pm 2 \%$ of their target stresses for the duration of the monitoring period. After loading the samples, total strains readings were taken 4 6 hours after and thereafter, daily for the 7 days, weekly for the next 3 weeks and monthly until the test was terminated.

\subsection{Shrinkage}

$100 \mathrm{~mm} \times 200 \mathrm{~mm}$ prisms were cut from the $710 \mathrm{~mm} \times$ $100 \mathrm{~mm}$ beam as described in section above. Demec targets were glued onto the shrinkage samples using quick-set glue similar to the creep samples. The samples were then put in a curing bath for 28 days. At 28 days, the samples were transferred to the same humidity and temperature controlled room as the creep samples and zero strain readings were obtained before the samples became surface dry. The two $100 \mathrm{~mm}$ square ends of the shrinkage samples were sealed with an epoxy to ensure an equivalent drying surface area as the creep samples. The shrinkage strains were measured using a $100 \mathrm{~mm}$ demec strain gauge. These readings were obtained at the same time as readings for companion creep samples.

\section{Preliminary results and discussion}

\subsection{Tyre Rubber Characterisation}

The relative density of the crumb tyre rubber aggregates was determined using a pycometer. The $2.36 \mathrm{~mm}$ and $1.18 \mathrm{~mm}$ crumb tyre rubber particles had a relative density of 1.11 and 1.06 for the $0.425 \mathrm{~mm}$ crumb rubber particles. The rubber particles are 2.65 and 2.77 times lighter than the andesite aggregate which had a specific gravity of 2.94 . The SEM microscopy revealed significant differences in the shape and texture of the crumb rubber sizes. Micrographs of the crumb rubber particles are shown in Fig. 2, Fig. 3 and Fig 4 below. The $2.36 \mathrm{~mm}$ and the $1.18 \mathrm{~mm}$ crumb rubber particles generally have a more regular and well defined angular shape. The edges are fairly clean cut in contrast to the $0.425 \mathrm{~mm}$ crumb rubber paricles that have an irregular and more puffy, fibrous structure. The surface texture is much smoother for the $2.36 \mathrm{~mm}$ and $1.18 \mathrm{~mm}$ crumb rubber than the $0.425 \mathrm{~mm}$ crumb tyre rubber particles.

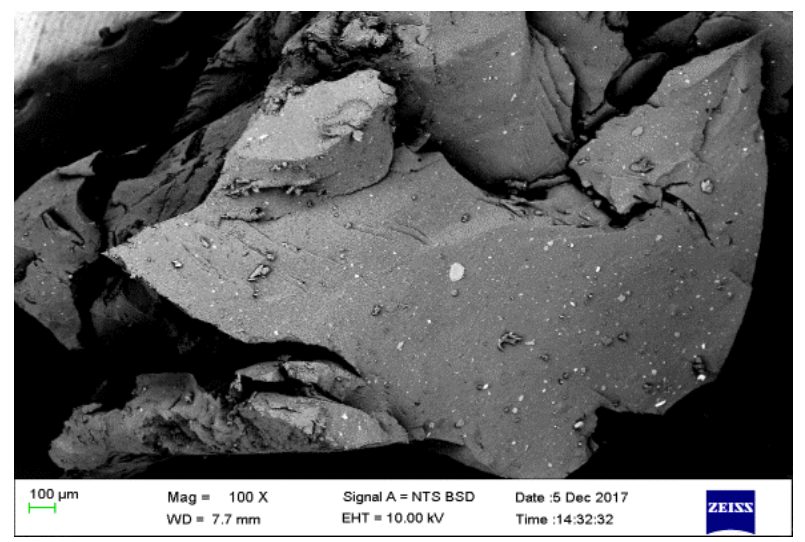

Fig 2. SEM micrograph of a $2.36 \mathrm{~mm}$ particle

\subsection{Slump and Compressive Strength}

The slump test results for all the concrete mixes is shown in Fig. 5 below. The results show that there is an improvement in workability of the concrete with the incorporation of rubber particles. The slump increased by $87 \%, 20 \%$ and $53 \%$ for the M8, M16 and M40 concrete mix respectively. The general increase in slump can be attributed to the low water absorption of tyre rubber when compared to mineral aggregates. İt is worth noting that the M8 mix had the biggest slump of all the mixes. It is difficult to attribute this behaviour to a 
particular tyre rubber particle attribute since the increase does not seem to follow a certain trend based on size.

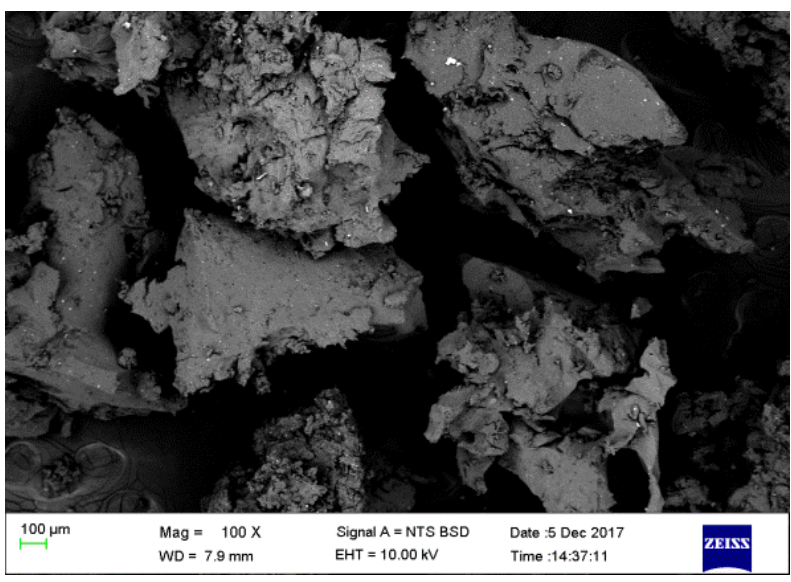

Fig 3 SEM micrograph of $1.18 \mathrm{~mm}$ particles

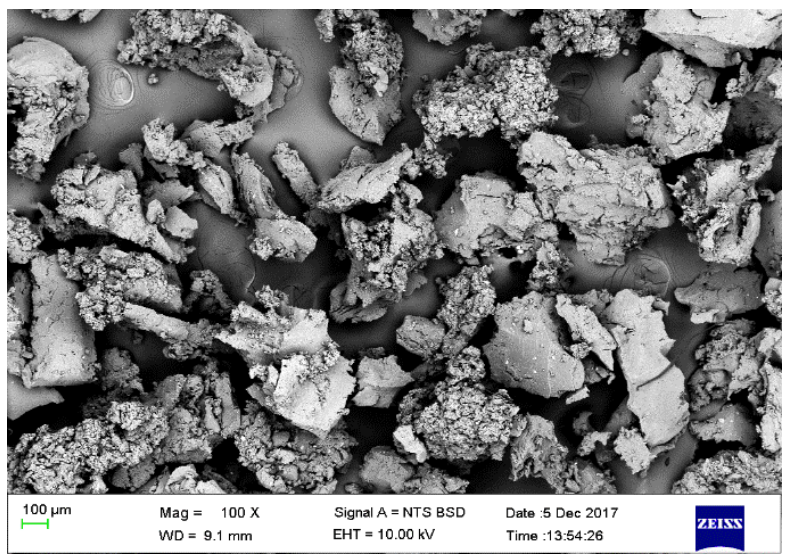

Fig 4. SEM micrograph of $0.425 \mathrm{~mm}$ particles

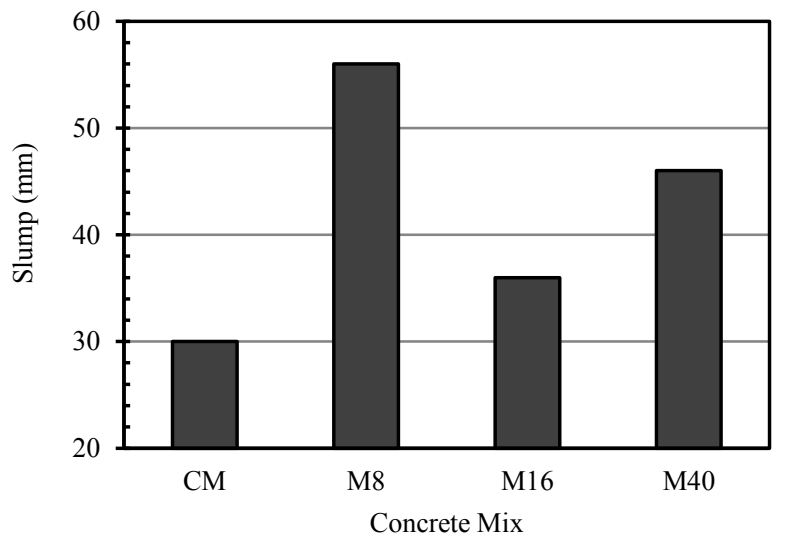

Fig 5. Slump Test

The compressive strength results for all the mixes are shown in Fig 6 below. The compressive strength of concrete decreased with the inclusion of crumb rubber content. The strength decreases by $22 \%, 23 \%$ and $27 \%$ for the M8, M16 and M40 mix respectively. The 0.425 $\mathrm{mm}$ crumb rubber particles produce the highest strength reduction when compared with the other two crumb tyre rubber sizes. There appears to be a trend of decreasing strength as the crumb rubber particle sizes become smaller. The smaller crumb rubber sizes result in greater strength reduction due to their shape which increases the air content of the concrete. The shape of the $0.425 \mathrm{~mm}$ rubber particles being more rugged and rough in the edges results in more air being lodged in the crevices thereby increasing the air content in the concrete mix thus reducing the strength of the concrete further.

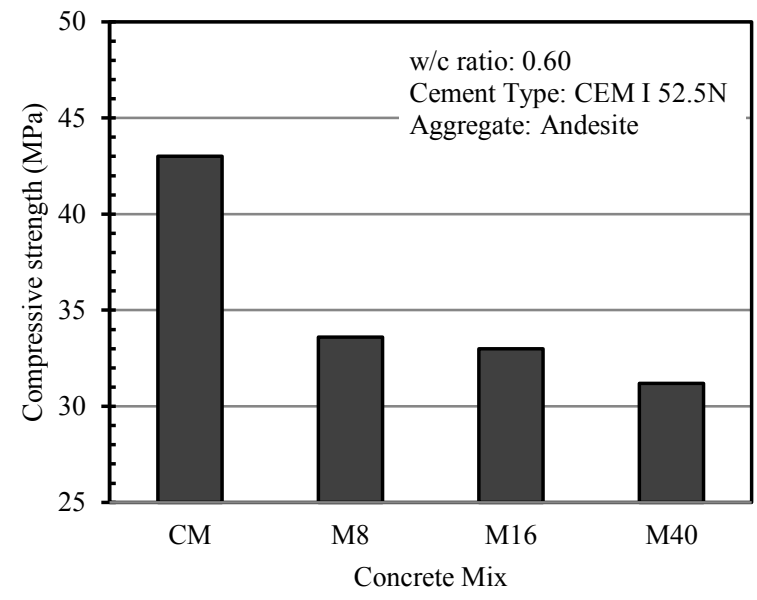

Fig 6. Compressive strength at 28 days

\subsection{Shrinkage and Creep}

The shrinkage and creep results are not presented in this paper; collection of the data is still undergoing. Preliminary results however show an increase in the shrinkage and creep deformation of the concrete when crumb rubber is added.

\section{Conclusions}

Based on the compressive and preliminary timedependant results, rubberised concrete has lower compressive strength than the control concrete mix for all crumb rubber sizes. Crumb rubber size has an effect on the strength of concrete, as the crumb rubber becomes smaller compressive strength decreases. After the final shrinkage and creep results have been compiled the results will be checked against design code recommendations to see if the rubberised concrete deformations lie within the prescribed limits.

\section{References}

1. M. Alexander, S. Mindess, Aggregates in Concrete. London and New York: Taylor \& Francis (2015)

2. I. Kesegić, I. Netinger, D. Bjegović, Recycled clay brick as an aggregate for concrete: Overview, Tech. Gaz., 3, 35-40 (2008)

3. F. M. Khalaf, Recycling of clay bricks as aggregate in asphalt concrete, in Proceedings of International RILEM Conference on the Use of Recycled Materials in Buildings and Structures, Barcelona, Spain,1, 56-65 (2004) 
4. R. Siddique, T. R. Naik, Properties of concrete containing scrap-tire rubber - an overview, Waste Manag., 24, 6, 563-569 (2004)

5. M. Nehdi, A. Khan, Cementitious composites containing recycled tire rubber: an overview of engineering properties and potential applications, Cem. Concr. Aggreg., 23, 1, 3-10 (2001)

6. M. Elchalakani, High strength rubberized concrete containing silica fume for the construction of sustainable road side barriers, Structures, 1, 20-38 (2015)

7. T. R. Naik, S. S. Singh, Utilization of discrded tires as construction materials for transportation facilities, The university of wisconsin (1991)

8. N. N. Eldin, A. B. Senouci, Rubber-Tire Particles as Concrete Aggregate, J. Mater. Civ. Eng., 5, 4, 478-496 (1993)

9. K. S. Malladi, Studies on rubberized cement concrete, Thesis (2004)

10. L. Zheng, X. S. Huo, Y. Yuan, Strength, Modulus of Elasticity and Brittleness Index of Rubberised Concrete, J. Mater. Civ. Eng., 20, 11 (2008)

11. K. C. Panda, P. S. Parhi, T. Jena, Scrap-TyreRubber Replacement for Aggregate in Cement Concrete: Experimental Study, Int. J. Earth Sci. Eng., 5, 6, 1692-1701 (2012)

12. S. Jain, To Study on Waste Tyre Rubber as Concrete (2014)

13. N. N. Eldin, A. B. Senouci, Rubber-Tire Particles as Concrete Aggregate, J. Mater. Civ. Eng., 5, 4, 478-496 (1993)

14. H. Rostami, J. Lepore, T. Silverstraim, I. Zundi, Use of recycled rubber tires in concrete, in Proceedings of the International Conference on Concrete 2000,391-399 (1993)

15. N. Segre, I. Joekes, Use of tire rubber particles as addition to cement paste, Cem. Concr. Res., 30, 9, $1421-1425$ (2000)
16. A. Fiore, G. C. Marano, C. Marti, M. Molfetta, On the Fresh/Hardened Properties of Cement Composites Incorporating Rubber Particles from Recycled Tires', Adv. Civ. Eng., 1-12 (2014)

17. F. Pelisser, N. Zavarise, T. A. Longo, A. M. Bernardin, Concrete made with recycled tire rubber: Effect of alkaline activation and silica fume addition, J. Clean. Prod., 1-7 (2010)

18. B. S. Thomas, R. C. Gupta, P. Mehra, S. Kumar, Performance of high strength rubberized concrete in aggressive environment, Constr. Build. Mater., 83, 320-326 (2015)

19. A. M. Neville, J. J. Brooks, W. H. Dilger, Creep of plain and structural concrete. London; New York: Construction Press (1983)

20. Z. P. Bažant, L. Panula, Practical prediction of creep and shrinkage of high strength concrete, Matér. Constr., 17, 5, 375-378 (1984)

21. F. P. Torgal, A. Shasavandi, S. Jalali, Tyre rubber wastes based concrete a review, in WASTES: Solutions, Treatments and Opportunities (2011)

22. M. H. Blumenthal, Producing Ground Scrap Tire Rubber: A comparison between ambient and cryogenic technologies, in 17th Biennial, (1996)

23. T. R. Naik, S. S. Singh, Utilization of discarded tires as construction materials for transportation facilities, CBU (1991)

24. A. Evans, R. Evans, The Composition of a Tyre: Typical Components. The Waste \& Resources Action Programme (2006)

25. SAB Standards, SANS 50197 Cement Part 1: Composition, specifications and conformity criteria for common cements (2013)

26. SAB Standards, SANS 50197 Cement Part 2: Conformity evaluation (2017)

27. SAB Standards, SANS 5863: Concrete Tests Compressive strength of hardened concrete (2006)

28. ASTM International, ASTM C512 / C512M-15, Standard Test Method for Creep of Concrete in Compression (2015) 